\title{
LEITURA CRIITICA - SINONÍMIA E PARASSINONÍMIA, FONTE DE INTERAÇÃO HISTÓRICA CULTURAL DISCURSIVA
}

Antonieta Laface ${ }^{(*)}$

Resumo: Trata-se do vocabulário temático, interatuante no contexto histórico cultural dos quinhentos anos Brasil. Para tanto, procura-se, nos princípios básicos do léxico, mobilizar a parassinonímia lingüística e a conceptual temática, de forma a explicar variações e efeitos de sentidos de unidades vocabulares da área da história, transpostas para a linguagem jornalística literária. Acredita-se encontrar, nas reflexões, caminhos para a sistematização de uma proposta de leitura crítica.

Palavras-Chave: discurso, leitura crítica, parassinonímia, sentido, léxico

\section{Introdução}

A "globalização" aparece, nos tempos atuais, como sendo um fenômeno que atinge povos e culturas, definindo-se na universalização do conhecimento, marcando presença no final de século. Fala-se da "globalização" da economia, da política, das realidades de mundo, das crenças, do imaginário. Credita-se a ela a solução de muitos problemas políticos e econômicos, sociais e ideológicos. Tem-se, por ela, a interação solidária dos povos. Estimula-se, com ela, a divulgação dos avanços da ciência, nas áreas do saber. Teme-se, também, pela unilateralidade radical no que tange às especificidades culturais de cada povo. Tenta-se, por essa razão, preservar essas especificidades, contando-se com a mediação da linguagem; fonte de interação e de cognição.

Nessa dimensão, a mundialização da linguagem, virtual ou não, exerce papel importante na divulgação de informações. Torna-se instrumento para o processo interativo da comunicação sujeito e universo - a discursividade. Nessa caso, a palavra abre-se nesse espaço interativo, traduzindo situações de uso das informações, de acordo com as exigências do grupo social. Sendo polissemêmica, produz sentidos, cujos efeitos se refletem na historicidade do universo humano. Posicionada no ato discursivo, determina-se pelo sujeito,

(") UNESP/Assis, Departamento de Lingüística. 
designa e descreve os fatos e os acontecimentos, formadores da cultura de um povo.

É, pois, no âmbito da "globalização" que a linguagem jornalística literária, por exemplo, se faz presente, traduzindo conceitos, transformando, através da palavra, realidades culturais em realidades universais; reconstruindo, na linha do tempo, a dimensão histórica do sujeito da ação no mundo e dele, no seu próprio universo cultural. "Brasil Quinhentos Anos", descrito nas páginas jornalísticas, mostra a formação cultural de um povo, marcado pelos traços étnicos de dominados e dominadores. $\mathrm{Na}$ projeção do passado sobre o presente, aparece a interatividade das raças, até porque a cultura lusitana se sobrepõe à indígena e a outras tantas sobre elas.

Objetiva-se, neste artigo, tratar do vocabulário temático, interatuante no contexto cultural literário e histórico dos quinhentos anos. Pretende-se mostrar, pelo princípio da parassinonímia, a projeção e os efeitos de sentidos das unidades vocabulares, dependendo da situação de uso. Dá-se à parassinonímia a condição discursiva, contando-se com a ampliação dos sentidos produzidos no ato comunicativo. Procura-se encontrar parâmetros para o vocabulário temático da área de história; projeção para a leitura crítica literária.

Sinonímia - princípio básico da parassinonímia

No universo da "globalização" da linguagem, os fatos históricos do "Brasil Quinhentos" avivaram-se. Projetaram-se nas telas da Internet e difundiram-se nas revistas, mostrando a origem de uma cultura que vem se formando ao longo dos séculos. Sucesso ou fracasso, os festejos tiveram espaço, dizendo bem a índole festeira do povo brasileiro. Assim, da alegoria carnavalesca aos andores nas procissões religiosas, Cabral aparece como "herói do descobrimento", presente em cada manifestação popular, em cada universo de crenças, em cada realidade de mundo.

Assim, ao lado do "herói do descobrimento", o "herói da Fórmula I" continua no pódio dos heróis nacionais. De herói em herói, cruzam-se os caminhos intrincados da "História Sagrada" com os da "Mulata do Carnaval", os da "Loura Carnavalesca" com os da "Alegoria Indigena", os da "Alegoria Religiosa" com os do "Bacanal de Herodes", numa mistura de épocas, de lugares, de 

CULTURAL DISCURSIVA

História. E as comemorações continuaram no protesto do "Povo Indígena", nas reivindicações dos "Sem Terra", nas manifestações dos segmentos sociais, nos estudiosos da linguagem, em que "descobrimento" parece compreender "achamento", "encontro", "invenção", "conquista", "redescobrimento".

"Brasil Quinhentos" revelou-se no espaço aberto de uma linguagem que se universaliza e, ao mesmo tempo, se credita nos mundos possíveis, nas realidades do grupo social. Em cada universo histórico cultural, a palavra torna-se fonte de produção de sentidos, de forma que passado e presente se mesclam e permitem a construção de novos universos de conhecimento, em que pese a compreensão sobre o mundo, em que se sustentem as projeções da história do homem sobre a história de um grupo.

Falar de sinonímia, nessa dimensão, é dizer uma linguagem que começa no plano do significado; é saber as situações de uso da língua nos diferentes contextos; é criar relações de sentido, mais do que uma simples relação de unidades lexicais que, tradicionalmente, estariam sendo intercambiáveis em todos os contextos. "Herói do descobrimento" e "Herói da Fórmula I" traduzem-se no espaço interno da índole cultural e étnica do povo, de forma a se projetarem na linha do tempo. Passado e presente sobrepõem-se, anunciam o futuro, em que "herói" e "descobrimento" designam fatos e definem, cognitivamennte, a história do "Brasil Quinhentos".

Nessa perspectiva, o vocábulo "herói", "nome dado pelos gregos aos grandes homens divinizados..." define-se no curso da História Universal, descrevendo o perfil "daquele que se distingue pelo valor ou por suas ações extraordinárias..." e que, portanto, passa a ser "exaltado, engrandecido... ${ }^{3}$ " pelo que representa, como o "Herói da Fórmula I" ou pelo que se torna; "personagem de uma aventura..., de uma descoberta" ", como o "Herói do Descobrimento" - sentidos que se produzem, conforme situações de uso circunstanciado e que, nesse uso, passam a ter registro no grupo.

\footnotetext{
Houaiss/95.

Houaiss/95.

Houaiss/95.

Houaiss/95.
} 
A figura do "herói" vincula-se a do "descobrimento" $e$ resgata os fatos históricos, recortando as realidades do passado, explicando o presente pelo que Cabral "encontrou", pelo que "achou", "inventou" ou "deixou para se conquistar". A palavra assume posição no discurso e deixa-se significar pelo que "Cabral teria conquistado... um nome por alguma importante descoberta marítima.. ${ }^{5}$." ou pelo que "o mestre da aventura (J. Verne) escreveu sobre Cabral", fazendo o contato de personagens históricos de épocas diferentes. Assim, Cabral contou com "Luís de Camões, que devia ilustrar no seu poema dos Lusíadas o valor e o espírito aventuroso de seus compatriotas". "J. Verne também descobriu o Brasil $^{7}$ "e, por esse fato, conduziu a dialogia da História, em que "descobrimento" estaria se distendendo no "encontro" da História de Cabral com a História da Fórmula I.

Desse modo, a "conquista" na história do "Brasil Quinhentos" traduz-se pelo "descobrimento", define-se pelo "vencer, cativar, ganhar, dominar...", abre-se em "achamento", numa ampliação de sentidos, de forma a que se possa falar, na atualidade, de "descobrimento" e "achamento"; de "descobrimento" e "conquista"; de "descobrimento" e "redescobrimento", no "descobrir de novo", no "tornar a descobrir". "Descobrimento" e "redescobrimento" dinamizam conceitos, mobilizam crenças, possibilitam a reorganização e a reconquista do espaço social histórico de um povo, de uma cultura em formação.

No pêndulo da história, o resgate de termos relacionados ao "descobrimento" permite o renascer do espírito das navegações, restringindo designações, ampliando sentidos, em que "boa parte das naus da esquadra cabralina tenha sido construída às pressas"; em que "navios malfeitos afundaram..."; em que "a esquadra de Cabral, composta de três caravelas e uma naveta de mantimentos era a maior que Portugal jamais enviara para singrar o Atlântico ...". E, no discurso jornalístico, o vocabulário temático reconduz-se,

\footnotetext{
Época, 20/02/00, p. 78.

Época, 20/02/00, p. 78.

Época, 20/02/00, p. 78.

Houaiss/95.

Época, 06/03/00, p. 58.
} 
LEITURA CRÍTICA - SINONÍMIA E PARASSINONIMIA, FONTE DE INTERAÇÄO HISTÓRICA 259 CULTURAL DISCURSIVA

sinonimicamente, por "embarcação", "nau", "caravela", "navio", mostrando o percurso histórico da navegação - do "descobrimento" ao "redescobrimento".

Nessa situação de uso, "embarcação", "termo genérico que designa os pequenos barcos..." ou "designação (mais genérica ainda) dada a toda construção destinada a navegar na água...." amplia-se e restringe sentidos, constrói dimensões temáticas do vocabulário em uso. Assim, "nau", "antiga embarcação a vela, de alto bordo, com três mastros e numerosas bocas de fogo; qualquer navio", aparece nas páginas jornalísticas, recuperando a história do século XVI. "Nau", ao ser definida por "qualquer navio", reporta-se à "embarcação de grande tonelagem, destinada a navegar em mar alto... ${ }^{10}$."

Assim, a "esquadra cabralina" navega pelos mares e pelo tempo, ao encontro do "Brasil Quinhentos", composta por suas "caravelas", "navios de velas latinas dos séculos XV e XVI, rápidas e de pequena tonelagem ${ }^{11}$ ". Nelas, Cabral marca o seu tempo, com elas, conquista o espaço, por elas, torna-se o Herói do Descobrimento, dialogando com a História, resgatando o seu Universo de Conhecimento, fazendo-se lembrar na História do Mundo. Eis o princípio básico da parassinonímia.

Parassinonímia - do lingüístico ao cognitivo

$\mathrm{Na}$ "globalização" da História Universal, recupera-se a "Carta de Caminha", a chamada "Certidão de Nascimento do Brasil". Nela, aparece a constatação do "encontro" das raças, delineando o espaço cultural dos povos, aportados no continente sul americano. Dos indígenas, reaviva-se a "conquista" da zona litorânea de um território chamado Pindorama, a Terra das Palmeiras. Dos europeus, ratifica-se a supremacia da "conquista", pelo "achamento" das terras americanas, na mais espantosa aventura de todas as que preencheram o milênio que se encerra. "A aurora de uma nova era nasce com o Brasil"1", relembra "os integrantes da frota que

\footnotetext{
10 Cf. no parágrafo Houaiss/95.

11 Houaiss/95.

12 Época, 24/04/00, p. 51.
} 
avistaram o cume de um "monte mui alto e redondo"13" e retoma o eixo da História no "redescobrimento". Entra-se no "tunel do tempo" dos quinhentos anos, para se rememorar a "primeira manhã do país", a dos portugueses num país chamado Brasil.

Nesse universo, em que passado e presente se fundem e o pêndulo da História jamais cessa de marcar época, evidencia-se a dinâmica das relações de sentidos, na dimensão sinonímica das unidades lexicais que, nas situações de uso da língua, circunstanciamse no espaço temático vocabular dos fatos históricos, reconduzindo valores culturais, reconstruindo universos, produzindo conhecimento. Assim é que "...os navios comandados por Cabral avistaram um monte... 14 , "termo geográfico, indicativo de terra alta, com arvoredo, matas, serra, cordilheira, montanha.. ". Relaciona-se, significativamente, à "montanha", "terra alta maior que monte 16 ". "Montanha" e "monte" marcam-se, preliminarmente, no plano da parassinonímia lingüística, diferenciam-se pelo estado de grandeza, numa mesma área de conhecimento. Na gradação sinonímica de “... serra, cordilheira, montanha...", demarcam-se os valores culturais dos povos que aqui se encontraram. Ampliam-se as relações de sentidos que, produtivamente, revelam a visão de mundo dos homens de Cabral, no "terra à vista", e a dos nativos que "vislumbraramo que lhes pareceu ser grandes montanhas flutuantes "17". Nesse aspecto, "caravelas" tornam-se, conceptualmente, "montanhas flutuantes".

Tratar da parassinonímia é partir do princípio de que toda relação de sentidos conduz a uma mobilização no plano do significado para abrir os espaços da discursividade. É ampliar relações decorrentes de uma rede de acontecimentos que emana da consciência. É mobilizar traços significativos do léxico temático de áreas do saber nas zonas de sentidos, conforme recortes das realidades de mundo, das crenças, das ideologias culturais. A significação resulta da relação entre unidades vocabulares, em que seja possível ser estável, estável no uso, circunstanciável no discurso.

\footnotetext{
13 Época, 24/04/00, p. 51.

14 Época, 24/04/00, p. 51.

15 Houaiss/95.

16 Houaiss/95.

17 Época, 24/04/00, p. 51.
} 

CULTURAL DISCURSIVA

Nessa perspectiva, a linguagem jornalística trilha por caminhos diferenciados de sentidos na dialogia da História, de forma a demonstrar que a palavra libera as demarcações do passado e do presente, em que personagens, protagonistas do universo de conhecimento, permanecem eternos e, por essa razão, aproximam-se e distanciam-se na linha do tempo e do espaço, numa projeção para o futuro, segundo mobilidades interativas do saber discursivo.

Nesse contexto, retoma-se o passado para se explicar o presente, recolocam-se os fatos na linha do tempo para dizer o inexplicável, no que "os navios ... avistaram - mais com alívio $e$ prazer que surpresa e espanto - o cume de um monte..." Essa retomada poderá estar respondendo a indagações sobre o "descobrimento", sobre o "achamento", sobre as condições de viagem por que passaram os homens de Cabral, sobre a visão de universo de cada personagem da História. E foi "mais com surpresa e espanto que com alivio e prazer, que os nativos vislumbraram o que lhes pareceu ser grandes montanhas flutuantes". "Surpresa e espanto" - coisa nunca vista pelos nativos" e "alívio e prazer" coisa a ser conquistada pelos portugueses" cobrem o espaço temático vocabular da parassinonímia conceptual, ultrapassando os limites da língua para dizer a índole de cada cultura, de cada povo, de cada universo de conhecimento.

É no sabor da "conquista" que os homens de Cabral encontram "alivio" e "prazer". É com espírito guerreiro que a "esquadra", "embarcações de guerra de um pais" ${ }^{18 "}$ avista terras a serem conquistadas. É pela "conquista” que essas embarcações tornam-se objeto de estudo, em que "historiadores supóem que boa parte da esquadra cabralina - pelo menos metade delas - tenha sido construída especialmente para aquela viagem. ${ }^{19}$ ".

Assim é que "a armada cabralina era completada por uma naveta (pequena embarcação) de mantimentos... Batizada não se sabe como, coube a ela (naveta) retornar a Portugal com as notícias sobre o achamento do Brasil.". E é no contexto sinonímico de "esquadra", que "armada" vai se definir como "frota, força naval de um pais ${ }^{20 ",}$

18 Houaiss $/ 95$.

19 Época,06/03/00, p.58.

20 Houaiss $/ 95$. 
recompondo, no discurso parassinonímico, a idéia de que o chamado "descobrimento" explica-se por "achamento".

No plano conceptual da parassinonímia, a unidade de sentidos é, por assim dizer, a palavra em uso no discurso. Nos efeitos produzidos, a intersubjetividade da linguagem tem sua função, em que se articulem mundo e sua relação com o sujeito; sujeito e sua relação com o mundo. A representação do universo cultural dá-se pelo uso que se faz da língua e é através dela que os sujeitos reais interagem no tempo e no espaço, de acordo com o funcionamento social histórico. As situações circunstanciadas de uso da língua integram-se nos processos de produção de sentidos, sabendo que é no grupo social que a voz do sujeito se faz presente e é nos enunciados formativos do saber que o sujeito constrói seu discurso, concretizando-se como indivíduo participante, interagindo com o universo de conhecimento.

Se Cabral é ou não o "Herói do Descobrimento", isto depende da visão histórica do mundo, das linguagens por que essa visão passa, da universalização dos fatos históricos, das comprovações documentárias, dos universos de crenças, do estado cultural de um povo, dado que "cinco séculos são passados após a chegada de Cabral.. ${ }^{21} . "$ e ainda "...precisamos saber quem somos, de onde viemos e para onde vamos"2.". Assim é que o "Herói do Descobrimento" encontra Colombo "herói", dialoga com Camōes, interage com Sena. No caminho interativo de passado e presente, encontram-se outros tantos "heróis". Do "Herói do Descobrimento" ao "Herói da Fórmula I", a História marca seu tempo, constrói seu espaço; espaço para a leitura crítica.

\section{Notas Conclusivas}

A parassinonímia abre caminhos para a ampliação e variabilidade de sentidos das unidades lexicais, dimensionadas no contexto histórico, cultural e ideológico do grupo social. Cada universo cultural tem sua história, seus princípios, seu modo de vida; suas particularidades. A identidade cultural de um povo determina-se pelo modo como esse povo vê o mundo, transpondo conceitos, reformulando posições, recompondo o universo do saber. Nesse

21 Época, $24 / 04 / 00$, p. 51.

22 Época, 24/04/00, p. 51. 

CULTURAL DISCURSIVA

aspecto, a "mundialização da linguagem" tenta assegurar, pelo menos em parte, as especificidades do grupo, tornando-se abrangente a todos os povos, particularizante em cada cultura.

Com base no princípio da sinonímia, a parassinonímia atende a situações de uso da língua e expande-se, produtivamente, no discurso, inclusive o literário. Permite construir e reconstruir o universo de conhecimento, a partir do lingüístico, em que pesem as relações de sentidos, resultantes da transposição de unidades do léxico para o campo da discursividade. Os efeitos dessas relações lexicais no discurso traduzem-se na reorganização do conhecimento, tendo-se presente a conexão do indivíduo e sua relação com o mundo, do mundo e sua relação com indivíduo, na composição de sua própria história, do seu próprio discurso.

Nessa dimensão, a proposta de uma leitura crítica vai muito além de atividades centradas no plano da língua. As estratégias de uma leitura crítica devem mobilizar conceitos, dependendo das circunstâncias de uso das unidades vocabulares e das condições temáticas por que passam essas unidades. Nesse aspecto, a descrição do objeto temático associa-se ao universo de conhecimento, traduzindo-se conforme os valores culturais de um povo. Ao mesmo tempo, a natureza desse objeto deve ser preservada, de forma a ser reconhecido em qualquer situação, sob quaisquer condições de uso. Qualquer proposta de leitura deve atender a essas considerações.

\section{Referências}

BUENO, E. A Aurora de uma Nova Era nasce com o Brasil. Revista Época, Rio de Janeiro. Edições Globo/24/04/00, p. 51.

BUENO, E. Um Lapso Histórico e suas Compensações. Revista Época, Rio de Janeiro., Edições Globo/15/11/99, p. 90 ..

BUENO, E. Navios Malfeitos Afundaram Cabral? Revista Época, RJ., Edições Globo,06/03/00, p. 98.

BUENO, E. Júlio Verne também Descobriu o Brasil. Revista Época, RJ., Edições Globo/20/02/00, p. 78.

CLAS, A., GROSS, G. Les Classes d'Objets et la Désambiguisation des Synonymes. Paris, Cahiers de Lexicologie, v.7, 1970. 
GALISSON, R.. Une Dictionnaristique à Géometrie Variable - au service de la lexiculture. Paris, Cahiers de Lexicologie, v. 70, 1977.

MARQUES, M.H.D. Aspectos Semânticos da Linguagem. Introdução à Semântica. Rio de Janeiro, Zahar, 1990.

PEREIRA, F. Sens et Subjectivité. Le Sens Linguistique, Littérature, Psychanalyse, Cahiers Charles V, Paris VII,CIRNA/1993.

VILELA, M. Léxico da Simpatia, Porto, Almedina/1980. 